\title{
Zwischen- und Endreinigung in einer Anlage
}

Für die Zwischen- und

\section{Endreinigung sowie die}

Konservierung von Automobil-

Einspritzkomponenten wurde

eine Mehrkammeranlage

entwickelt, die einen flexiblen

Betrieb und kurze Taktzeiten

ermöglicht.

$\mathrm{D}$ ie neue Anlage (Hexa) von LPW ist 13 Meter breit, fast 9 Meter tief und modular aufgebaut. Das Mehrkammer-System kommt in der Automobilzuliefererindustrie für Einspritzkomponenten mit höchsten Reinheitsanforderungen zum Einsatz und wurde unter folgender Aufgabenstellung entwickelt: Zwischen- und Endreinigung von Stahl- sowie Edelstahlteilen inklusive Korrosionsschutz der endgereinigten Stahlkomponenten. Die Anlage schafft Taktzeiten von etwa 4 bis 5 Minuten bei der Zwischenreinigung und 8 bis 12 Minuten bei der Endreinigung.

\section{Nachteile von offenen}

Mehrbadsystemen eliminiert

Vorgaben dieser Art, vor allem in puncto Durchsatz, waren bis dato nur in Mehrbadsystemen umsetzbar. Doch die offenen Bäder dieser Anlagen verursachen meist massive Einschränkungen der waschmechanischen Möglichkeiten sowie Umflut- und Filtrationsleistungen. Hinzu kommen der hohe Wartungsaufwand sowie die hohen Energiekosten aufgrund der starken Wärmeverluste.

Durch Weiterentwicklung des Modularsystems PowerJet ist es nun gelungen, diese Nachteile mit dem neuen Mehrkammersystem zu beheben. Die Anlage verfügt über getrennte Spül-

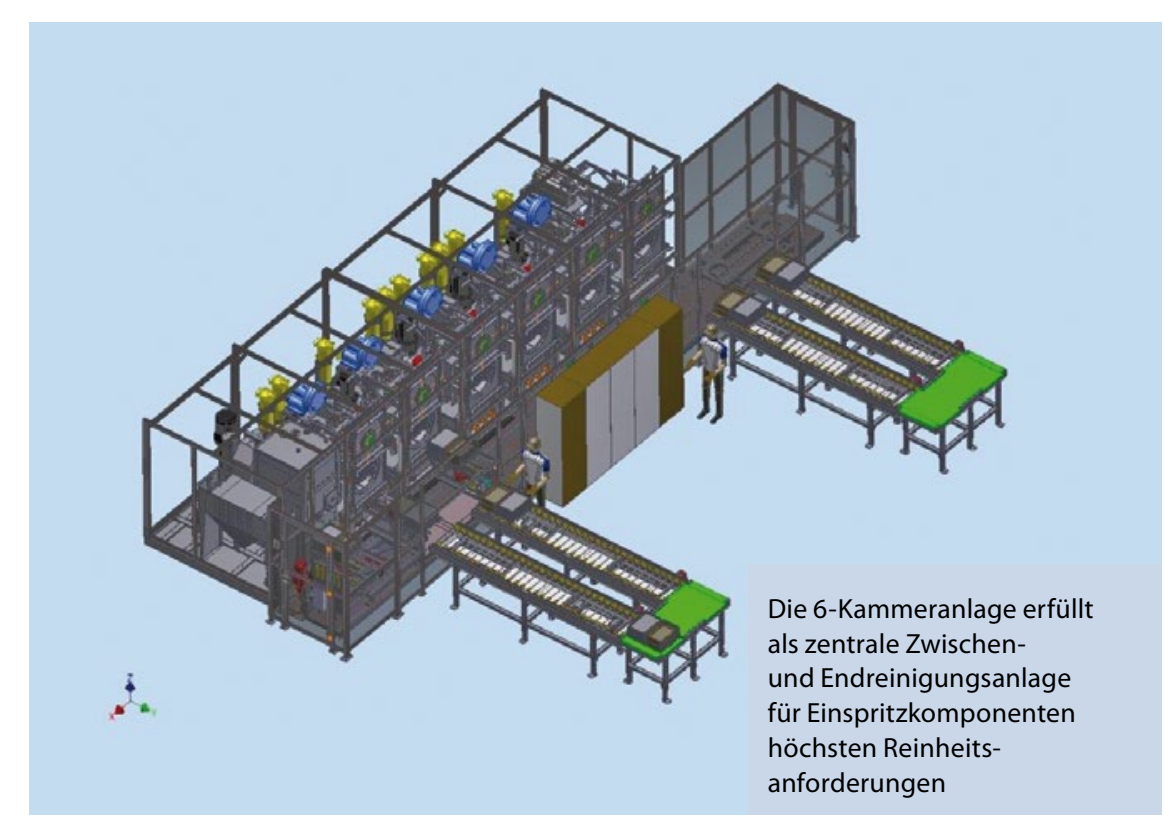

und Trocknungskammern für Stahlbeziehungsweise Edelstahlkomponenten sowie eine Destillationsanlage zur Medienaufbereitung. Gereinigt wird mit der Kombination Ultraschall plus Injektionsfluten. Die Anlage verfügt über ein PC-basiertes Steuerungssystem inklusive Prozessverfolgung über RFID sowie frequenzgesteuerte Pumpentechnik. Die Beladung ist sowohl manuell als auch durch Roboter möglich. Für ein hohes Maß an Flexibilität, auch bei stark variierenden Chargen-

Anforderungen, sorgt die leistungsfähige Shuttle-Automation.

Die zentrale Anlage bietet aufgrund der Mehrkammertechnologie ein Höchstmaß an Variabilität in der Anwendung sowie eine im Vergleich zu Mehrbadanlagen deutlich bessere Energiebilanz. I

\section{Kontakt::}

LPW-Reinigungssysteme GmbH, Riederich, Tel. 07123 3804-0, info@lpw-reinigungssysteme.de, www.lpw-reinigungssysteme.de

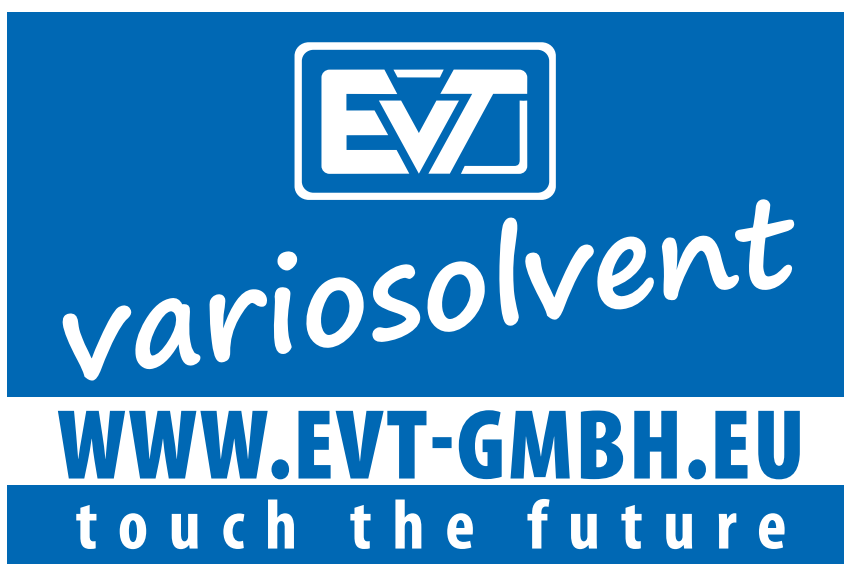

